\title{
BIOTECHNOLOGY - THE ROLE OF PERCEPTIONS OF CONSUMERS
}

\author{
P van Heerden (BSI TechKnowledge/ International Data Corporation) \& N Lessing (RAU)
}

The development of Biotechnology is aimed at creating improved products. Without the acceptance of biotechnology enhancements by consumers, the development of new products will be hampered. Consumers in different countries perceive genetic engineering differently. In this article the views of foreign and local consumers are investigated.

Keywords: biotechnology, consumer perception, genetic engineering, genetic manipulation, genetic modified

\section{PERCEPTION OF FOREIGN CONSUMERS}

The success of biotechnology depends to a large extent on the perceptions of consumers. Consumers should be able to make an educated and informed decision on whether or not to purchase a genetically enhanced product. This is crucial to the biotechnology industry.

Consumer fears are particularly strong in Europe, where a series of food scares, ranging from mad cow disease to contaminated Coke, have undermined consumer's trust in the European regulatory authorities. While $90 \%$ of Americans do believe the US Department of Agriculture statements on biotechnology, only 12\% of Europeans trust their national regulators (Ellahi 1994:7). Many European companies like Nestlé, Danone, Marks \& Spencer and Unilever are responding to the consumer concerns by marketing products free from any genetic modification, but stating that biotechnology does have significant benefits (Enriquez \& Goldberg, 2000: 102).

Canadian consumers, on the other hand, are choosing genetically enhanced foods over conventional varieties. According to Monsanto (2001: Internet), customers at Birkbank Farms in Ontario have chosen for the second consecutive year genetically enhanced (Bt) sweet corn and potatoes over conventional counterparts. The genetically enhanced crops were labelled to show not only product enhancement, but also listed the amount of pesticide used. This concurrently impressed consumers to choose the enhanced crops $60 \%$ of the time. At the Birkbank Farm market, both traditional and enhanced sweet corn and potatoes have been harvested and are now available fully labelled with information on the genetic enhancement and the amount of insecticide used.

Consumers were particularly impressed with the lack of pesticides usage in producing the genetically enhanced crops. Because of genetic engineering Bt corn required no insecticides and the Bt potatoes proved effective against the Colorado potato beetle, Ontario's number one potato pest. The conventional corn and potatoes, by contrast, required multiple insecticide sprays.

The Canadian example proves that not all is lost. Some countries are more willing to accept genetic engineering than others. What is very interesting to note in the Canadian example is the labelling of the products. Consumers were firstly given the opportunity to choose between the conventional variety and the genetically enhanced version, and secondly the consumers were informed of the purpose of the genetic enhancement, and in this case it meant a reduction in chemical sprays because resistance (against the potato beetle) was already "built-in". 


\section{THE SOUTH AFRICAN REGULATORY ENVIRONMENT}

South Africa has a well-established, traditional biotechnology industry and scientific capacity, ranging from food to the mining industry. It has produced one of the largest brewing organisations in the world (South African Breweries); it makes wines that compare with the best; it has created many new animal breeds and plant varieties, some if which are used commercially all over the world and it has competitive industries in the manufacture of dairy products such as cheese, yoghurt and maas and baker's yeast and other fermentation products.

However, South Africa has not been successful to extract value from the recent advances in biotechnology, particularly over the last 25 years with the emergence of genetics and genomic sciences.

Already many organisations and public institutions elsewhere in the world are offering products and services that have arisen from the new biotechnology. In the US there are 300 public biotechnology organisations with a market capitalisation of $\$ 353$ billion and an annual turnover of $\$ 22$ billion.

The strategy of South Africa is designed to make up for lost ground and stimulate the growth of similar activities in South Africa. Biotechnology can make an important contribution to the national priorities, particularly in the area of human health, food security and environmental sustainability (Parker et al., 2001:i).

The regulatory institutions of South Africa play an important role in biotechnology. These institutions should aim to achieve the following: firstly, they must create thorough regulations and extensive safety tests to ensure the approved products are safe to consume and not harmful to the environment, secondly the regulations and tests should be in such a format that it promotes commercialisation of the products and thirdly, establish a good image and relationship with consumers to ensure the consumers trust the regulatory institution.

Any biotechnology organisation that operates in SA needs to consider the regulatory institutions in the strategies they follow. These institutions do not just regulate the products they also determine if the products will be allowed on the market, which in turn affect the success and profitability of the biotechnology organisation.

In June 2001 the DACST produced a national biotechnology strategy for South Africa. The strategy proposed new institutional arrangements. The most important aspect of the new institutional arrangements is the establishment of the Biotechnology Advisory Committee (BAC). According to the Parker et al. (2001:61) the BAC has the following purposes:

- To be an advisory committee under the auspices of the economic cluster in government and reporting to the DACST.

- To implement the national biotechnology strategy.

- To identify national biotechnology priorities.

- To issue the requests for proposals for the establishment of regional innovation centres within the established guidelines for the promotion of synergy in the biotechnology community of South Africa. 
- To recommend to the National Advisory Council on Innovation (NACl) and other government funding agencies the appropriate programmes for expenditure on biotechnology in South Africa.

- To monitor and report the impact of biotechnology expenditure.

- To promote the investment of venture capital in biotechnology and the search for industrial partners.

- To investigate resource mobilisation into biotechnology.

\section{THE PERCEPTION OF SOUTH AFRICAN CONSUMERS}

The acceptance of consumers is an integral part of establishing a successful biotechnology industry in South Africa. A survey was recently conducted at RAU University to test the respondents' views on biotech foods or in other words, food produced via biotechnology.

Seventy-one post-graduate students were surveyed. The students majored in business-orientated courses. The group had a $100 \%$ response rate.

The demographics of the respondents were as follows:

- $\quad$ There were more male $(59 \%)$ than female $(41 \%)$ respondents, most of the respondents were in the 18 to 25 years category (52\%) and most respondents were not married (60\%).

- The respondents were mainly of the white demographic segment (79\%) and believed in the Christian religion (95\%). [The Christian religion has no real dietary restrictions. Therefore, the answers of respondents were based on personal reasons and not on religious dietary restrictions.]

- The respondents represent many different industries and the majority had 3 to 5 years of work experience.

Each statement was developed in such a way that the respondent gives a subjective view on genetically engineered foods. The statements were in such a format that the respondents could agree or not agree to the statements. The statements were answered on a six-point Likert-scale, where numbers are associated with different responses (the responses are easily classified between strongly disagree or strongly agree).

\section{ST ATEMENTS AND RESPONSES}

Sixteen statements were presented to the respondents. The six points on the scale were as follows: 1 = strongly disagree; 2 = disagree; 3 = disagree somewhat; 4 = agree somewhat; 5 = agree and 6 = strongly agree.

An analysis of the responses recorded indicated that a three way split could be presented: 
- reject indicates that the statement is rejected, meaning that the respondent either disagree strongly (Likert value $=1$ ) or disagree (value $=2$ )

- undecided indicates that the responded has no definite point of view on the statement and either disagree somewhat (value $=3$ ) or agree somewhat (value $=4$ )

- support indicates support for the statement and represents either agree (value $=5$ ) or strongly agree (value $=6$ ) with the statement.

The responses on the statements are summarised below. The reporting on these statements are done in a different sequence than the questions in the questionnaire. The questions in the questionnaire were on purpose not ordered by grouping similar questions in sequence because that would lead the respondents to "ideal" answers. In filling in the questionnaire, there was a time limit. This was done to eliminate a rational analysis of the questions. The implication of this approach was that the results were the intuitive reaction of the respondent on the issue formulated in the statement.

The interpretation of the results need to be done with caution.

STATEMENT: I require more information about the benefits and risks of genetic engineering

RESPONSE $\quad$ Reject $=7.6 \%$; Undecided $=10.6 \%$; Support $=81.8 \%$

This was the last question in the questionnaire. This question (and the ranking of this was done on purpose) dealt with the issue whether the respondent was really in a position to evaluate these statements. A massive $81.8 \%$ of the respondents agreed with the statement that they need to have more information about the risks and benefits of genetic engineering. Five respondents thought that additional information was not required. Closely related to this statistic is that the remainder of 15 questions had an average of $39.1 \%$ of undecidedness. That means that in nearly two out of five statements the respondents were not able to take in a firm stand on the relevant issue. Bear in mind that the respondents were all senior students in management, that they represent many different industries and that the majority of them had 3 to 5 years of work experience. This implies that at least a significant portion of them was in management and decision-making positions in their respective work areas. They are typically people that will have to decide on issues relating to genetic engineering. These two aspects indicate the requirement that the industry take on an extensive information campaign. This campaign need to focus on he managers in decision-making positions on the one hand, but also on the consumers at large being the eventual buyers of the GE products.

STATEMENT: I will purchase products that are genetically engineered

RESPONSE: $\quad$ Reject $=19.7 \%$; Undecided $=53.5 \%$; Support $=26.8 \%$

The response is high in uncertainty with about a quarter of the respondents that are willing to buy these products. It was expected to have greater support for buying GE products for an "educated" group of the consumers.

STATEMENT: $\quad$ Purchasing GE food should result in cost savings

RESPONSE $\quad$ Reject $=21.1 \%$; Undecided $=29.6 \%$; Support $=49.3 \%$ 
Nearly a half of the respondents expect cost savings for the consumer (either directly or indirectly). A large portion of the respondents (nearly $30 \%$ ) was not able to take in a position on this).

STATEMENT: I will only purchase GE food if it is cheaper

RESPONSE $\quad$ Reject $=38.0 \%$; Undecided $=40.8 \%$; Support $=21.1 \%$

Only one in five respondents will buy GE food on cost considerations alone. The indecision factor here is again a high $40.8 \%$.

STATEMENT: $\quad$ Consuming GE food should result in improved health

RESPONSE $\quad$ Reject $=16.9 \%$; Undecided $=46.6 \%$; Support $=36.6 \%$

About one in six respondents imply that the use of GE food would be hampering health. This is a serious misconception that should be addressed in the public information campaign. Only one in three respondents believe the beneficial value of GE foods.

STATEMENT: $\quad$ Prescribed medicines contain no genetically engineered ingredients RESPONSE $\quad$ Reject $=52.9 \%$; Undecided $=41.4 \%$; Support $=5.7 \%$

More than half of the respondents accept that medicines in fact contain GE material! Another $40 \%$ are not sure about the facts. Less than $6 \%$ of the respondents is of the opinion that medicines do not contain genetic engineered substances. This might be interpreted as a go ahead on this issue, or at least not a serious opposing of the idea.

STATEMENT: $\quad$ GE food is safe to consume

RESPONSE $\quad$ Reject $=22.5 \%$; Undecided $=52.1 \%$; Support $=25.4 \%$

This question is closely related to the two reported on above. Whereas $36.6 \%$ of the respondents supported the improved health impression resulting from using GE foods, only $25.5 \%$ reckons that these products are safe to consume. Those $16.9 \%$ of the respondents rejecting the idea of improved health by using GE foods has now increased to $22.5 \%$ not believing it is safe to use GE foods. This inconsistency in response can only be explained in terms of a very high level of undecidedness $(41.4,46.6$ and $52.1 \%$ respectively) on these three questions.

STATEMENT: $\quad$ Consuming GE food is against my religion RESPONSE $\quad$ Reject $=63.8 \%$; Undecided $=26.1 \%$; Support $=10.1 \%$

It was reported above that $95 \%$ of the respondents were from the Christian religion, where no real dietary restrictions were in force. It was therefore expected to have a high rejection rate on this statement. However, the reject rate on this statement was only $63.8 \%$. Even, when one combines the reject responses with the respondents undecided about their religion's point of view on genetic manipulation, then the total amounts to less than $90 \%$. This indicates that respondents experience great need to be informed about the fundamentals of their religion, and how these would apply their principles and believes to new technologies.

STATEMENT: $\quad$ GE food is unnatural

RESPONSE $\quad$ Reject $=18.3 \%$; Undecided $=38.8 \%$; Support $=43.7 \%$ 
Only $18.3 \%$ of the respondents classify GE foods as natural. Nearly $40 \%$ are unsure whether the manipulation of the genetic composition changes the natural state to unnatural. Nearly $44 \%$ of the respondents maintain that GE food is indeed unnatural.

STATEMENT: $\quad$ GE foods should be used as animal feed

RESPONSE $\quad$ Reject $=41.4 \%$; Undecided $=38.6 \%$; Support $=20.0 \%$

Only one in five respondents support the idea to use GE foods as animal feed, although there are many benefits in (e.g. cheaper and with higher nutritional value). Half of the remainder is against the idea and the other half is undecided on the issue.

STATEMENT: $\quad$ I am hesitant to consume GE foods

RESPONSE $\quad$ Reject $=17.4 \%$; Undecided $=44.9 \%$; Support $=37.7 \%$

This statement is closely related to the previous statement. Approval of GE food for humans $(17.4 \%)$ is closely related to support of GE food as animal feed (20.0\%); rejecting GE foods for humans (37.7\%) is close to rejecting it for animal feed $(41.4 \%)$.

STATEMENT: $\quad$ Animals should be cloned for human consumption

RESPONSE $\quad$ Reject $=62.9 \%$; Undecided $=27.1 \%$; Support $=10.0 \%$

This statement is closely linked to the previous one, but the results are somewhat contradictory. Only $17.4 \%$ indicated their openness to use GE foods, but $10.0 \%$ of the same respondents support animal cloning (= GE cloning) for human consumption (= GE foods). A total of $37.7 \%$ of the respondents are hesitant for using GE foods, but $62.9 \%$ reject animal cloning for food. It seems that the perceptions of the respondents are that genetic manipulation on plants are acceptable, but cloning of animals are rejected. This may also indicate another underlying fear: if scientists were able to clone animals, they would eventually be able to clone humans. The high Christian complement of the respondents will object to this idea.

STATEMENT: I will use prescribed medicine containing GE animal ingredients

RESPONSE $\quad$ Reject $=35.2 \%$; Undecided $=29.6 \%$; Support $=35.2 \%$

$17.4 \%$ of the respondents indicated that they are hesitant to consume GE foods, but about double the number would be willing to use prescribed medicine with GE animal products. However, for every one willing to use medicine with GE animal ingredients, there is one that is against the idea and almost one that cannot make up his mind on the matter.

STATEMENT: I would rather use GE medicine before I use GE food

RESPONSE $\quad$ Reject $=18.2 \%$; Undecided $=47.0 \%$; Support $=34.8 \%$

The last two questions are related. The number of respondents supporting the use of medicine containing GE animal ingredients is the same as those that would rather use GE medicine than GE food. However, $35.2 \%$ reject the idea of using GE animal ingredients in medicine, but still (only) $18.2 \%$ would rather use medicine than food that are subject to genetic manipulation. 
STATEMENT:

I am concerned about the negative impacts of genetic engineering on the environment

RESPONSE

$$
\text { Reject }=18.3 \% \text {; Undecided }=23.9 \% \text {; Support }=57.7 \%
$$

Concern for the environment is one of the hot topics of the day. That could influence the high response rate of $57.7 \%$. This figure could be interpreted as concern for the environment as such, and does not necessarily imply that genetic engineering per se would harm the environment.

STATEMENT: It is safe to consume artificial sweeteners

RESPONSE $\quad$ Reject $=24.6 \%$; Undecided $=47.7 \%$; Support $=27.7 \%$

Nearly half of the respondents are undecided on this issue, whereas that in support is only marginally higher than those against using artificial sweeteners. It needs to be remembered that the artificial nature of food or medicine not necessarily implies that it was genetically manipulated.

\section{CLOSURE}

Whether or not South African consumers will accept biotechnology is unclear. South Africans have not yet been introduced to biotechnology and little information exists on the subject in South Africa. South African consumers are far less informed than consumers in countries like the UK, Canada, Australia and USA.

The South African respondents were positive and open towards biotechnology. Although, serious reservations exist they are still willing to try GE products.

Cloning is a very sensitive issue. In all the questions relating to cloning, the respondents were against the idea to use cloning for any purposes. The respondents were also concerned over the environmental impact of biotechnology and the consumption of such products.

When the respondents were asked if they require more information on biotechnology more than $90 \%$ agreed to some extent that they need more information. This proves that South African consumers are uninformed about biotechnology.

Awareness of genetic engineering is low and is associated with high risks and low benefits. Consumers need information on the safety, guidelines, approval procedures and tests these products must endure before they are released onto the market or into nature. An increase in public awareness is necessary to facilitate the acceptance of genetic engineering but it will also allow consumers to make informed choices in the selection or rejection of genetically modified products and contributes to a large extent to the development of the technology.

Influential people need to be educated because they are in the position to influence the public opinion. Journalists, retailers, businessmen, consumers, media of all sorts and influential individuals need to be educated to report the facts rather than the fantasy. Projects to educate scholars and teachers about the basics of genetic engineering are also needed to educate consumers about genetic engineering. Leaflets, forums, exhibitions, labelling, workgroups, seminars and any other applicable form of education are needed to educate all applicable parties involved. 
Addressing and resolving these ethical and moral issues are the critical factors of the biotechnology industry. If the biotechnology industry aims to develop to its full potential, then these issues should be on top of their priority list.

\section{BIBLIOGRAPHY}

ELLAHI B. 1994. Genetic engineering for food production - what is it all about? British Food Journal, 96(8). [Internet: http://www.emerald -library.com/brev/07096hb1.htm.]

ENRIQUEZ J \& GOLDBERG RA. 2000. Transforming life, transforming business: the life -sciences revolution. Harvard Business Review, March-April. Boston: Harvard Business School.

MONSANTO. 2001. The biotech advantage. [Internet: http://www.biotechknowledge.com/advantage/index. html.]

PARKER I, BOTHA F, HIDE W, JEENAH M, MADOLO N, MUGABE J, SIBARA M, THOMSON J, WALWYN D \& WINGFIELD B. 2001. A national biotechnology strategy for South Africa. Pretoria:Department of Arts, Culture, Science and Technology, June. 